\title{
Ultrasound as diagnosis tool for grading bronchiolitis: where are your limits lost?
}

\author{
Maria Elena Latrofa ${ }^{1}$ (D) $\cdot$ Antonio M. Esquinas ${ }^{2} \cdot$ Leonardo Costa $^{1}$ \\ Received: 18 April 2019 / Revised: 30 June 2019 / Accepted: 30 June 2019 / Published online: 23 July 2019 \\ (C) Springer-Verlag GmbH Germany, part of Springer Nature 2019
}

\section{To Editor,}

We read the interesting article from Supino and colleagues [4]. The use of ultrasound in bronchiolitis diagnosis is an emerging topic. The validation of ultrasound scores integrated with clinical ones may allow the reduction of chest x-ray use [2]. Recent studies have shown the validity of ultrasound compared with chest X-ray in bronchiolitis [1]. The score used in this study is simple and easy; this can increase the inter-observer agreement. The aim of this study is to evaluate the predictivity for the need of respiratory support; it could be very useful for therapy and hospitalization or pediatric intensive care admission. Although studies that used other ultrasound scores [3] have shown a good correlation between ultrasound and clinical score, there are some key aspects to clarify for a proper clinical extrapolation. First, in this study, the correlation between the two scores was not evaluated although this was one of the study aims. Why? It could be interesting also to explain the reason why there is no correlation between the ultrasound score and the oxygen saturation on Emergency Department admission, which is an important parameter for the decision about respiratory support [5]. Secondly, the study shows a correlation between the ultrasound score and oxygen therapy duration, but the linear regression showed that includes the clinical score is the only explanatory variable: does it

See related article, https://doi.org/10.1007/s00431-019-03431-7

Communicated by Peter de Winter

Maria Elena Latrofa

mariaelena.latrofa@aosp.bo.it

Antonio M. Esquinas

antmesquinas@gmail.com

Leonardo Costa

leonardo.costa@aosp.bo.it

1 Pediatric Anesthesia and Intensive Care, S. Orsola Malpighi Hospital, via Massarenti 9, 40138 Bologna, Italy

2 Intensive Care Unit, Hospital Morales Meseguer, Avda. Marqués de los Velez, s/n, 30008 Murcia, Spain depend on the validity of the ultrasound score compared with the clinical score? This has important impact on clinical decisions. We agree that the ultrasound is repeatable; this would allow to follow the evolution of bronchiolitis; it would have been interesting to calculate the ultrasound score in various moments after Emergency Department admission to assess its ability to anticipate the patient's clinical deterioration. Multicenter studies on larger populations including patients even with severe bronchiolitis are required.

Authors' contributions All authors contribute with this preparation.

\section{Compliance with ethical standards}

Conflict of interest The authors declare that they have no conflict of interest.

\section{References}

1. Caiulo VA, Gargani L, Caiulo S, Fisicaro A, Moramarco F, Latini G, Picano E (2011) Lung ultrasound in bronchiolitis: comparison with chest X-ray. Eur J Pediatr 170(11):1427-1433. https://doi.org/10. 1007/s00431-011-1461-2

2. Miller RW (1995) Special susceptibility of the child to certain radiationinduced cancers. Environ Health Perspect 103(suppl 6):41-44

3. Özkaya AK, Yilmaz HL, Kendir ÖT, Gökay SS, Eyüboğlu İ (2018) Lung ultrasound findings and bronchiolitis ultrasound score for predicting hospital admission in children with acute bronchiolitis. Pediatr Emer Care. https://doi.org/10.1097/PEC. 0000000000001705

4. Supino MC, Buonsenso D, Scateni S, Scialanga B, Mesturino MA, Bock C, Chiaretti A, Giglioni E, Reale A, Musolino AM (2019) Point-of-care lung ultrasound in infants with bronchiolitis in the pediatric emergency department: a prospective study. Eur J Pediatr 178(5):623-632. https://doi.org/10.1007/s00431-019-03335-6

5. Viscusi CD, Pacheco GS (2018) Pediatric emergency noninvasive ventilation. Emerg Med Clin N Am 36(2):387-400. https://doi.org/ 10.1016/j.emc.2017.12.007

Publisher's note Springer Nature remains neutral with regard to jurisdictional claims in published maps and institutional affiliations. 